\title{
Would Responsive Parenting Reduce the Rate of Childhood Obesity?
}

\author{
Porteous $\mathrm{ZT}^{*}$ \\ Department of Paediatrics, NHS Greater Glasgow and Clyde, Scotland
}

*Corresponding Author: Porteous ZT, Department of Paediatrics, NHS Greater Glasgow and Clyde, Scotland, Tel: +447714767175; E-mail: ztporteous@doctors.org.uk

Received date: March 02, 2018; Accepted date: March 23, 2018; Published date: March 27, 2018

Citation: Porteous ZT (2018) Would Responsive Parenting Reduce the Rate of Childhood Obesity? J Child Obes Vol No 3 Iss No: 1: 5.

Copyright: (C) 2018 Porteous ZT. This is an open-access article distributed under the terms of the Creative Commons Attribution License, which permits unrestricted use, distribution and reproduction in any medium, provided the original author and source are credited.

\section{Commentary}

Multiple studies can be found to support the statement that faster weight gain increases your risk of lifelong obesity and associated co-morbidities such as, cardiovascular disease and Type 2 diabetes [1]. Childhood obesity has reached epidemic levels in developed countries and is continuing to rise in developing countries. $10 \%$ of the world's school children are estimated to be carrying extra weight; one quarter of these children are clinically obese. In addition $1 \%$ more children are becoming obese every year [2].

The Intervention Nurses Start Infants Growing on Healthy Trajectories (INSIGHT) study randomized primiparous mothers and their newborns [3]. The study was performed in one maternity ward in Pennsylvania with follow up visits at home by the health visitor. The intervention group (145 infants) received responsive parenting (RP) training; focusing on sleeping, soothing and feeding. The control group (146 infants) received dose-matched information about home safety. The study raises some interesting questions about how infant response training may reduce the rate of weight gain and subsequent obesity rates at one year of age. The infants were visited at home aged 4, 16, 28 and 40 weeks. The visits focused on age-appropriate sleep hygiene and avoidance of feeding to sleep, emotion regulation encouraging alternate strategies to feeding the fussy infant, satiety cues and developmentally appropriate social activities. The outcomes recorded were infant weight gain and overweight status at one year compared with infants in the control group. 125 patients from the intervention group (86\%) and 125 patients from the control group (86\%) completed follow-up at one year [4].

An intervention promoting responsive parenting behaviours can promote healthy growth trajectories in infancy can potentially reduce obesity risk. The INSIGHT study provides supportive evidence to empower professionals to encourage parents to respond to their infants by alternative soothing, sleeping methods and not use feeding as a means of pacification.

Setting of the satiety center is the key in this critical developing period. Overfeeding in the neonatal period can permanently alter microglial profiles within the developing brain, thus predisposing the individual to lasting central pro- inflammatory profile that contributes to overactive immune responses for life [5].

Environmental factors, lifestyle choices and social environment play a pivotal role in rising obesity worldwide. Obesity can profoundly affect the child's health, social, and emotional wellbeing as well as self-esteem. It is associated with poor academic performance and a lower quality of life experienced by the child [6]. Adolescent experiences vary with their weight status. Teenage girls, who are overweight or obese, report more severe adverse social, educational and psychological effects. Obese (as well as underweight) boys also report some adverse social and educational effects [7].

Parental factors contribute to the obesity rates in children. Children learn by mimicking parents' and peers' preferences, intake and willingness to try new foods [8]. Feeding practices tend to fall into three categories-rewarding, child's control and pressure; which turn out to be significant predictors of childhood obesity. Additionally, the child's weight, family income and parental educational level have an effect on the choice of feeding strategies used by the family. They have an additional impact on the child's food intake [9]. Therefore, behaviour alteration may be a better intervention for healthy infants rather than focusing on calorie content or restrictive eating. Studies have shown that weight loss is more likely to be achieved where family-based approaches are used [10], although significant long-term weight loss is very difficult to achieve. This could be down to family motivation, peer pressure and increasing social pressures of the modern world. Society has increasing sedentary lifestyles, easier access to 'fast-food' and barriers to change [11]. Other studies have shown that the risk of obesity is lower in breastfed infants [12] but this is not evident in this study.

The most significant result to highlight from the INSIGHT trial is that the responsive parenting group had $5.5 \%$ obesity levels at one year vs. $12.7 \%$ in the control group. This suggests that an early Public Health initiative focusing on providing behavioural guidance and support for new mothers could have a significant impact on our evolving obesity crisis. Responsive parenting classes could improve bonding and attachment, patient safety as well as the educational value of soothing, sleeping and feeding. These public health campaigns may succeed where other government weight loss plans have failed. They focus on preventative measures of obesity reduction rather than 
implementing change to engrained habits. Prevention is the only realistic solution to the growing obesity rate. Early school and home based interventions, such as responsive feeding, are likely to have a bigger impact as these are times when the population is generally more susceptible to change [13]. Focusing on this may, over time, decrease childhood obesity and lead to a healthier society as a whole.

\section{References}

1. Baird J, Fisher D, Lucas P, Kleijnen J, Roberts H, et al. (2005) Being big or growing fast: Systematic review of size and growth in infancy and later obesity. BMJ 331: 929-931.

2. Lobstein T, Baur L, Uauy B (2004) Obesity in children and young people: A crisis in public health. Obes Rev 5: 4-85.

3. Savage JS, Birch LL, Marini M, Anzman-Frasca S, Paul IM (2016) Effect of the INSIGHT responsive parenting intervention of rapid infant weight gain and overweight status at age 1 year: $A$ randomized clinical trial. JAMA Pediatr 170: 742-749.

4. Marshall Z, Delahunty C (2018) The INSIGHT responsive parenting intervention reduced infant weight gain and overweight status. Arch Dis Child Educ Pract 103: 57-58.

5. Ziko I, De Luca S, Dinan T, Barwood JM, Sominsky L, et al. (2014) Neonatal overfeeding alters hypothalamic microglial profiles and central responses to immune challenge long-term. Brain Behav Immun 41: 32-43.
6. Sahoo K, Sahoo B, Choudhury AK, Sofi NY, Kumar R, et al. (2015) Childhood obesity: causes and consequences. J Family Med Prim Care 4: 187.

7. Falkner $\mathrm{NH}$, Neumark-Sztainer $\mathrm{D}$, Story $\mathrm{M}$, Jeffery RW, Beuhring $\mathrm{T}$, et al. (2001) Social, educational, and psychological correlates of weight status in adolescents. Obes Res 9: 32-42.

8. Patrick H, Nicklas $T$ (2005) A review of family and social determinants of children's eating patterns and diet quality. J Am Coll Nutr 24: 83-92.

9. Kroller K, Warschburger P (2008) Associations between maternal feeding style and food intake of children with a higher risk for overweight. Appetite 51: 166-172.

10. Harder T, Bergmann R, Kallischnigg G, Plagemann A (2005) Duration of breastfeeding and risk of overweight: A meta-analysis. Am J Epidemiol 162: 397-403.

11. Ebbeling C, Pawlak D, Ludwing D (2002) Childhood obesity: Publichealth crisis, common sense cure. Lancet 360: 473-482.

12. Barlow S, Dietz W (1998) Obesity evaluation and treatment: expert committee recommendations. Pediatrics 102: e29.

13. Campbell K, Waters E, O'Meara S, Kelly S, Summerbell C (2002) Interventions for preventing obesity in children. Cochrane Database Syst Rev 2: CD001871. 